\title{
The Role of Big Data in Enhancing Customer Experience in UAE Retail
}

\author{
Shital Vakhariya ${ }^{1} \&$ Kirti Khanzode ${ }^{2}$ \\ ${ }^{1}$ Industry Interface project at SP Jain School of Global Management, Dubai \\ ${ }^{2}$ Communications at SP Jain School of Global Management, Dubai \\ Correspondence: Shital Vakhariya, Senior Manager, Industry Interface project at SP Jain School of Global \\ Management, Dubai.
}

Received: October 14, 2018

Accepted: November 22, 2018

Online Published: November 27, 2018

doi:10.5430/ijba.v9n6p76

URL: https://doi.org/10.5430/ijba.v9n6p76

\begin{abstract}
Purpose: The objective of this research was to identify critical success factors for the adoption of Big Data in UAE retail. The use of Big Data, in this case, focused on improving its system of recommendations for a better understanding of consumer behavior and its impact on consumer experience.
\end{abstract}

Design/Methodology/Approach: The research was done through interviews \& observation of shopping patterns. A semi - structured interview script was used for the interviews.

Findings: Based on the results, we outline some propositions related to the opportunities and obstacles for the implementation of Big Data in UAE retail.

Originality/Value: The main contribution of the research was the identification of relevant factors to the adoption of Big Data that were not considered as critical for the adoption of previous technologies.

Research Rationale: Few years ago, retailers had no idea who was buying what and from where they are buying and where not so bother about customer experience. Now Big Data helps retailers understand individuals' needs, allowing them to create segments to target. Big Data will help in understanding the buying trend. Not may study are conducted in UAE retail. This study will help to understand the adoption and role of Big data in UAE retail customer experience.

This paper show how can big data analytics help to improve the retail business and can be applied in the sector and help in decision making.

Keywords: big data, retail, UAE, customer experience

\section{Introduction}

The current era of the consumer, with shoppers have more choices and control than ever before. They will be offered with choices of products and services, often personalized to their specific needs and wants. Consumers will continue to demand price and quality transparency along with a wide range of convenient fulfilment options. Overall, the retail experience is poised to become more inspirational, exciting, simple and convenient, depending on the consumer's ever-changing needs.

The key drivers of success over the next decade will be centered on building a deep understanding of and connection to the empowered consumer, promptly incorporating disruptive technologies, embracing transformative business models in both the offline and online space, and establishing key capabilities. With this transformation, companies will face challenges of cut throat competition.

Due to cutthroat competition and dynamic consumer behavior, marketers need to focus more on how they bring value to their customers. Relying on the past success, past heavy trademarks and banking on traditional offerings will keep the organization in the Red oceans. Today, the marketer needs to interact more with their customers, getting an in depth understanding of the experience and adopting the same approach towards the industry's non-customers. Big data can help in this blue ocean approach.

Big data can be a great help in understanding complex consumer behavior for marketers. Marketers with the help of big data, use company owned and public data to explore customer behavior, usage patterns and preferences. Big data also helps to search new customers through automatic segmentation and targeting. Big data helps in personalization 
and targeting the right prospects which will have a very big impact on overall sales and profitability in the long run, which leads to customer loyalty. Big data allows real-time decision making.

At the time of omni-channel zone: web, mobile, phone, chat, in person, through sales people, ordering systems, loyalty programs, etc., Big Data helps a company in getting a detailed picture of their customers. It allows a deep dive into customer wants and helps to predict future outcomes on the basis of historical trends. Hence, marketers can create, personalize \& maximize user experience and thereby increasing the conversion rate.

\section{Literature Review}

\subsection{Big Data}

Big Data has become a buzz word nowadays and industries have used and benefited benefit from, Big Data including the retail industry, globally. There has been a lot of raw data which cannot be analysed and can have a huge impact on the operations of organisations now and in the future. However, most companies at an early stage with their Big Data journey" (Hurwitz et al. 2013).

\subsection{Big Data Landscape in the UAE}

Although Big Data has become a buzz world, still most companies at an early stage with their Big Data journey (Hurwitz et al. 2013). According to the Industry reports, retail and banking are some of the top data-intensive industries in the UAE. Oil and gas, finance, and telecom sectors are also using technology to boost customer engagement and satisfaction. According to research conducted by International Development Company (IDC), investment in business analytics in the Middle East in 2014 was predicted to increase at a compound annual growth rate of more than $20 \%$ in the coming few years. Roughly $40 \%$ of the Chief Information Officers (CIOs) in the Middle East are planning to invest in big data and analytics technologies, which made UAE one of the fast-growing countries in the region in terms of big data analytics.

Analytics are changing the various industry at a fast pace as more organizations begin to realize the importance of big data, and how it will drive successful marketing decisions based on insights gained from customer intelligence and predictive analytics. Retail is growing leaps and bound by using big data. According to MarketsandMarkets report, the retail analytics market is expected to reach USD 5.1 billion by 2020, boosted by increasing demand for customized analytics solutions in the emerging economies of MEA and APAC. According to Dubai Chamber of Commerce, UAE retail market to be worth US\$ 54.5billion in 2017.

Although, data analytics is at a nascent stage In the Middle East, companies will understand the importance of investing in this leading to a significant adoption of advanced analytics processing tools in the future too. In early 2017, Majid Al Futtaim started a School of Analytics and Technology designed to help the company enhance its advanced analytical capabilities. The school will deliver several education programmes to employees focused on enhancing their understanding of how analytics can be used to improve the delivery of unique and engaging experiences.

According to Marcel Yammine, General Manager, Gulf \& Emerging Markets at SAS in terms of technological advancements, the UAE and regional retail and other sectors have significantly evolved in the recent years. They have started realizing the role of big data analytics in enhancing better customer service and experience. Just from the buzzword, Big data is becoming a reality for an increasing number of companies in the UAE and other GCC countries. The Big Data concept is starting to gain some traction at the local level, especially within the most data-intensive industries. Adoption of Big Data in the GCC is still in its early days when compared with other regions like Europe and North America, but it is clear that awareness around the concept and its potential business impact is rapidly rising across the region. There is a paucity of skilled resources to handle the vast data and even the receptiveness is very poor.

\subsection{Retail Industry}

Retailing is defined as "business activities involved in selling goods and services to consumers directly for their personal, family, or household use" (Berman and Evans 2013). Retailers are the front face to the consumers (Duermyer 2013).

According to Euromonitor International UAE's retail sector value stood at $\$ 56.6$ billion at the end of 2016, and the retail sales turnover is expected to exceed $\$ 71$ billion by 2021 . According to LinkedIn, retail \& hospitality are the UAE's fastest growing industries over the past 15 years. Hence the study of customer experience is very vital here.

Even according the Companies who offer business analytics solutions for retailers, delivering a smarter shopping experience by understanding consumer behavior patterns is one of the key areas. 


\subsection{Applications of Big Data in the Current Industry}

For marketers, the customer experience is a focal point. Having a fantastic experience with your company, the customer makes repeat purchase, becomes loyal and refers the company to their friends, family, and acquaintances compared to customers who have had an ordinary or 'not so great' experience. There are multiple companies who benefitted by using big data.

Amazon used the huge data on its customers in advertising algorithms to improve customer relations and deliver an efficient customer service experience. Phillippines based Globe Telecom, teamed with IBM and Nokia to deploy an SOA-based service creation and delivery platform. The American Express Company used big data to analyze and predict consumer behavior.

Starbucks used big data to estimate the potential success of each new location, taking information on location, traffic, area demographic and customer behaviour into account. UAE based Emirates Airlines used big data in its customer interactions and to enhance their experience on- board.

\section{Research Methodology}

\subsection{Objective of the Study}

$>$ To understand the adoption of Big data in UAE.

$>$ To understand how companies, leverage Big Data to increase customer experience, loyalty and profitability.

$>$ To find the gaps and recommend best practices followed across the world.

\subsection{Research Strategy}

Qualitative Research: It involves the methods to collect tends to be words, rather than numbers, in the form of transcripts, or fieldwork notes. That data is typically unstructured, and statistical methods cannot be used in its analysis" (Timmons 2005). The interviews with 30 industry experts. The primary data was collected via expert interviews in retail industry. Considering the nature of this study, with focus on pre-identified areas for big data applications in retail operations from the literature review, semi-structured interview (open ended questions) is chosen as the method to obtain primary data.

The proposed methodology will incur three stages to complete the research and come to a suitable overall answer to the question:

\section{"How can the Big Data help in enhancing customer experience in the retail industry?"}

1. Gain insights into the usage of Big Data in UAE by reviewing publications and other journals from online sources, best practices reports published across print and digital media. Extensive secondary research has been undertaken.

2. Conduct interviews with selected experts and users in the area of Big Data Analytics and gain practical insights into the existing usage and problems that need to be resolved.

3. Based on the data gathered on the best practices followed across sectors using big data to enhance customer experience, propose possible solutions which will potentially enhance the customer experience and loyalty and yield in increased revenues to companies.

\subsection{Sample Size}

Random Sampling, 30 Top and mid-level managers in retail industry were interviewed.

\subsection{Hypothesis}

a. Data analytic is at a nascent stage in the UAE Retail

b. Use of Big data has a positive impact on the customer experience

\subsection{Conceptual Framework}

The Conceptual Framework enables us to understand how this research is performed and the overall flow of the Research Framework model implementation. 


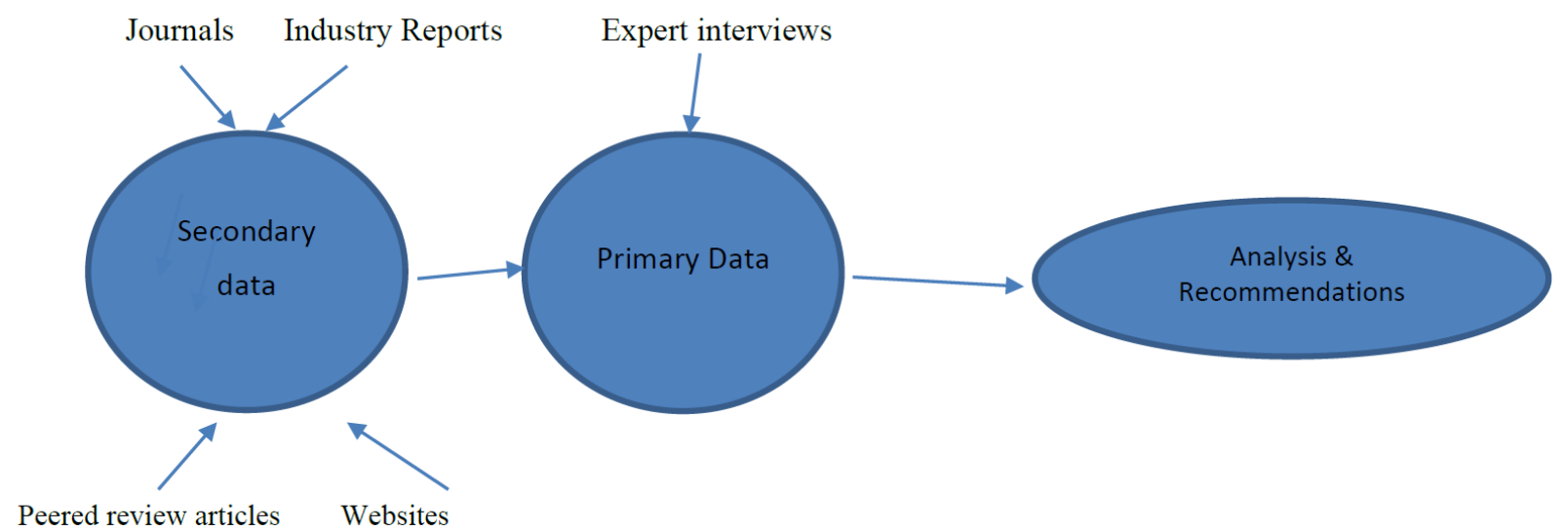

Figure 1

\subsubsection{Research Framework Model}

The primary \& secondary data is collected as above, and as per the flow shown in the diagram, analysis is performed in terms of Qualitative. To validate the qualitative analysis performed, experts were requested to endorse the same.

\subsubsection{Statistical Analysis}

The research study was built around relevant secondary data, industry knowledge enriched by interviews of retail experts. For a better and more accurate research study, various articles, journals, websites, books, research papers and case studies were deeply studied.

\section{Data Analysis \& Conclusion}

The objective of this research was to identify opportunities and obstacles to the implementation of Big Data in UAE retail and how use of Big Data to gain a better understanding of consumer behavior and enhancing customer experience. The adoption of Big Data is a part of strategic transformation process, from a traditional retailer aiming to become a data oriented company.

Basis interview, it is found that, for retail in UAE, customer experience is of prime importance. Here, Retailers do collect data majorly through emails and there is also increase in amount of data. They do have metric to measure the impact and success rates of customer engagement however it is in traditional format and even its data warehouse which integrates internal and external sources of information is under development. They still use emails or onsite/instore interaction for customer sourcing data. Hence, we can say that data analytics is still in the nascent stage in UAE retail. This proves hypothesis 1 right.

Among all, Fashion \& technology retail has been keener on using Big data as compared to the other sectors to enhance their customer experience in the last one year. According to the respondents, to improve customer experience, they need to put lots of efforts on follow ups and the process is not fully covered by IT systems. Hence, they see the scope of using Big data to remove data redundancy. This proves Hypothesis 2 right again.

Another frequent challenge, the retailers of UAE are facing is the talent gap which is not restricted to the technical profile, but also to behavioral aspects like curiosity and desire to learn. To overcome this, organizations need to train their people internally and also count on the acquisition of external competencies, such as consultants.

Finally, consumer sharing quality information is another challenge in itself. Big data could help filtering information, accurately predicting customer need which could help in enhancing customer experience.

The limitations of the study are as follows: as a result of the exploratory research method, with interviewing 30 industry experts. The results can't be generalized, yet they set a base for future investigations which may use the propositions suggested to study the implementation of Big Data in different organizations and sectors.

\section{Acknowledgement}

I acknowledge to my peers, collogues an mdy family for their moral support and cooperation. I also ensure that all coauthors have affirmed the final version of the paper and have agreed on its final publication. 


\section{References}

Berman, B., \& Evans, J.R. (2013). Retail Management A Strategic Approach, 1. Harlow, Pearson Education Limited.

Big Data Companies. (n.d.). Retrieved from https:/www.datamation.com/big-data/big-data-companies.html

Davenport, T., \& Dyche, J. (2013, May). Big data in Big Companies (White paper), 1-31.

Eaton, C., et al. (2012). Understanding Big Data Analytics for Enterprise Class Hadoop and Streaming Data, 1. New York, The McGraw-Hill Companies.

George, G., Hass, M., \& Pentland, A.S. (2014). Big data and management. Academy of Management Journal, 57(2), 321-326. https://doi.org/10.5465/amj.2014.4002

Hayashi, A.M. (2014). Thriving in a Big Data World. MIT Sloan Manag, 55, 35-39.

Hurwitz, J., et al. (2013). Big Data for Dummies, 1. New Jersey, John Wiley and Sons, inc.

Jones, R. (2015, December). UAE betting big on big data, as CIOs plan analytics investments. Retrieved from http://www.zdnet.com/article/uae-betting-big-on-big-data-as-cios-plan-analytics-investments/

Korolov, M. (2013). 15 most powerful Big Data companies. Retrieved 17 December 2013, from http://www.networkworld.com/slideshow/114134/\#slide1

Manyika, J., Chui, M., Brown, B., Bughin, J., Dobbs, R., Roxburgh, C., \& Byers, A. (2011). Big Data: The Next Frontier for Innovation, Competition, and Productivity, 1-143.

Marr, B. (2015). Big Data: A Game Changer in the Retail Sector. Retrieved from https://www.forbes.com/sites/bernardmarr/2015/11/10/big-data-a-game-changer-in-the-retail-sector/3/\#4113054 e6b32

Marshall, M.N. (1996). Sampling for qualitative research. Fam. Pract., 13, 522-526. https://doi.org/10.1093/fampra/13.6.522

McAfee, A., \& Brynjolfsson, E. (2012). Big data: The management revolution. Harvard Business Review, 90(10), 60-68.

Navin, H., Focus, G.N., \& Hina, N. (2017, April). Gulf Education: Why big data skills are in demand. Retrieved from

http://gulfnews.com/gn-focus/special-reports/gulf-education/gulf-education-why-big-data-skills-are-in-demand1.2010887

Retrieved from http://www.tradearabia.com/news/REAL_317822.html

Sadaqat, R. (2018). UAE retail sector continues to grow. Khaleej Times. Retrieved from https://www.khaleejtimes.com/business/retail/uae-retail-sector-continues-to-grow

Timmons, S. (2005). RLO: Qualitative and Quantitative Research. 